\title{
EL ESTADO Y LA EDUCACIÓN NACIONAL*
}

\author{
Valentín Letelier Madariaga**
}

EXCMO. SEÑOR, SEÑORES:

Una y otra vez se ha manifestado, en ocasiones análogas, dentro y fuera de este recinto, cuál es el propósito que se persigue al entrelazar en una misma corona ${ }^{3}$ los laureles que la juventud obtiene en las nobles lides de la inteligencia con aquellos que los padres de la Patria obtuvieron al caer en los campos de la gloria.

El propósito como todos vosotros los sabéis, es grabar de una manera perduraciones en el corazón de las nuevas generaciones, de aquellas que se preparan a empuñar próximamente las riendas del Estado, la más noble de las tradiciones políticas de Chile, cual es, que la prosperidad y la grandeza de este pueblo van indisolublemente vinculadas al constante desarrollo del espíritu nacional y de la enseńanza pública.

Es, en efecto, política tradicional al que honra a la República chilena la cariñosa atención que siempre se prestó por los Gobiernos de todos los partidos a las instituciones de educación popular; y esto, no con el anal intento de formar doctores, gramáticos y académicos, sino como lo expresaron los senadores de 1818, con el nobilísimo intento de formar buenos ciudadanos, esto es, ciudadanos capaces de cooperar a los fines sociales del Estado y de la política.

Bajo de este respecto, creo yo, señores, que, sin renunciar a la tarea más noble y al medio más eficaz de gobierno, un Estado no puede ceder a ningún otro poder social la dirección superior de la enseñanza pública. Para el sociólogo y para el filósofo, bajo el respecto indicado, bajo el respecto moral, gobernar es educar, y todo buen sistema de política es un verdadero sistema de educación, así como todo sistema general de educación es un verdadero sistema político. Es, por tanto, doctrina esencialmente materialista, indigna de todo republico de espíritu superior, la de que el Estado no debe curarse más que del cuerpo y del orden material de la sociedad. ¡No, señores! Las tradiciones invariables de la política chilena, no menos que los dictados de la sana filosofía, nos enseñan que el Estado tiene también cura de almas y corazones, como quiera que su misión más elevada no es la de atender a la conservación del orden actual o material, sino la de atender al desenvolvimiento del orden eterno o moral.

Discurso pronunciado por Valentín Letelier Madariaga en la sesión solemne celebrada por la Universidad el 16 de Septiembre de 1888. Fuente original: Letelier, Valentín. La lucha por la Cultura. Miscelánea de Artículos Políticos y Estudios Pedagógicos. Santiago, Chile: Imp. y Enc. Barcelona, 1895, pp. 43-53.

** El autor aquí hace alusión a la práctica de repartir los premios escolares en los días de las fiestas patrias. 
En lo antiguo no se comprendían de otra manera los deberes del Estado. El más notable tratado político de Platón es un verdadero tratado de educación; y no fue un cualquiera, fue el príncipe de los pensadores y de los filósofos. Fue el incomparable Aristóteles el que sentó que la educación debe guardar armonía con la organización política del Estado; que la educación debe ser atención preferente de los republicos; que en todas partes donde la educación es descuidada, el Estado tiene que sufrir rudos golpes; que es grave error creer que en estas materias cada ciudadano es dueño absoluto de sí mismo, pues todos pertenecen al Estado, del cual son elementos; que si uno solo, por vicio de educación es indisciplinado, el Estado mismo se contamina con este desorden; que la verdadera igualdad resulta de la educación reglada por buenas leyes, etc. Para nosotros, concluía, es evidente que la ley debe reglar la educación y que la educación debe ser común ${ }^{1}$. Esto se escribía dos mil años ha; pero responde tan positivamente a las más vivas y permanentes necesidades de la sociedad humana, que parece haberse escrito ayer no más, en el seno de alguno de los Estados más cultos, y hasta hoy mismo conserva toda la frescura y lozanía de las verdades eternas y universales, que nunca envejecen y ostentan en todos los tiempos y lugares la juventud y la belleza del primer día.

En nuestra propia época vemos que las dos cabezas mejor organizadas de la filosofía contemporánea, cuales son August Comte y Herbert Spencer, se cuentan a la vez entre los que han tratado más a fondo los problemas relativos a la política y a la educación pública, reanudando así, después de veinte siglos, las tradiciones sentadas por las dos cabezas mejor organizadas de la filosofía griega.

Para el inmortal fundador de la filosofía científica, ningún poder podría prescindir del apoyo espiritual, porque lo que en política se llama fuerza es un mero concurso de voluntades; y este concurso (agrega), si se puede formar ocasional y transitoriamente por una unión de intereses, no se puede mantener y desarrollar sino al doble influjo de una comunidad de sentimientos y de una comunidad de opiniones ${ }^{2}$.

Por eso, los Gobiernos más fuertes, esto es, más aptos para cumplir sus fines, no son aquellos que cuentan con un ejército más numeroso, más disciplinado, más aguerrido. Son aquellos que cuentan con el apoyo más decidido de aspiraciones realmente sociales, pudiéndose afirmar categóricamente que el Gobierno absoluto no puede ser popular sino allí donde existe la absoluta unidad de creencias; y que, por la inversa, todos los medios imaginables de opresión no sirven sino para mantener precariamente el orden material; pero no para crear el orden social allí donde el espíritu nacional está fraccionado por la diversidad de creencias y doctrinas.

Nunca dispuso en lo antiguo el poder temporal de tantas fuerzas materiales como el presente; jamás ensayaron los gobiernos medios tan poderosos de dominación; y la más arguciosa

1 Aristóteles. La política. Libro I, Cap. V; Libro V, Cap. I; y Libro VIII, Cap. VII.

2 Recomendamos para este punto Comte, August. Principios de filosofía positiva. Madrid, Espańa: La España Moderna, 1948. 
de las tiranías de otras edades no pudo inventar armas de aniquilamiento tan desastrosas como las armas de fuego de nuestros días. Sin embargo, nunca fue menos estable el orden social ni más inconsistente que en nuestros tiempos.

En todos los Estados cultos, las leyes suceden precipitadamente a las leyes, y aun las constituciones a las constituciones; reformas todavía no bien maduradas suplantan aun reformas todavía no bien maduradas suplantan a reformas todavía no bien ensayadas; y aquellas instituciones, la propiedad, la familia, el Estado mismo, que parecían inconmovibles porque tienen sus raíces en las profundidades de los tiempos prehistóricos, son violentamente azotadas por el vendaval y se muestran débiles para resistir a la tormenta. ¿Cuál es la causa de este estado convulso de las sociedades que dura hace ya un siglo y que las inhabilita para acometer y realizar obras radicales y duraderas? Es, señores, que no hay unidad de creencias; y que por lo mismo, en los gobiernos, sujetos a cambios continuos de personal, no hay fijeza de miras. Es que no existe un interés social que ligue a todos en una cooperación común. Es, en fin, que en el sistema de inevitable tolerancia en que todos los partidos y sectas tienen que vivir, cada uno se condena a la impotencia respecto de los demás, o se ve reducido en los casos de mayor poderío a obrar a medias, a contemporizar con las pretensiones opuestas, a transigir continuamente, dejando así siempre suspensa la solución definitiva de todos los problemas sociales y políticos.

Por eso, en todos los tiempos se han hecho reiterados esfuerzos para fundar el Gobierno de los pueblos en algún sistema de educación, propio a crear la indispensable convergencia de voluntades. Porque, en efecto, el fin social de la enseñanza es justamente ése, la convergencia de todos los corazones a un mismo propósito y de todos los entendimientos a una misma fe, con el deliberado intento de producir el desarrollo armónico de todas las fuerzas activas de la sociedad. Al presente, es verdad, o se destacan claramente este fin y esta influencia de la educación pública, porque no rige un sistema homogéneo de enseñanza; y el que rige no puede, por su naturaleza intrínsecamente contradictoria, imprimir un rumbo bien determinado a los educandos. Antes bien, los condena a perpetuas fluctuaciones, a dudas y perplejidades mortificantes.

En particular nuestra Universidad ${ }^{3}$ adolece de graves deficiencias que en gran parte la inhabilitan para cumplir su elevada misión. Para no mencionar más que las capitales, sin hablar ahora del empirismo general de su enseñanza es sabido que la más noble de sus facultades, la llamada a ser el verdadero seminario del profesorado secundario y a servir en este carácter de lazo de relación entre el instituto superior que crea la ciencia y los institutos secundarios que la difunden, la facultad de filosofía y humanidades, en fin, no existe sino en el papel y en el hombre. Es también sabido que por esta misma causa, aquellas ramas de la ciencia que atańen al orden moral, que son las ramas que más realzan su aplicabilidad social y las que la elevan a la dignidad de una filosofía general, no están hasta ahora representadas por una sola cátedra.

Referencia directa a la Universidad de Chile. 
Afortunadamente, señores, unos dos nuevos proyectos que se trata de llevar a cabo, el de un curso de administración y política y el de un seminario pedagógico, están destinados a llenar en gran parte esos vacíos; y la Universidad espera de vos, Excmo. Señor, que así como habéis puesto decisión en su creación inicial, pondréis perseverancia en su realización completa. Para llevar a cabo estos adelantamientos, el Estado encontrará un terreno perfectamente llano, porque en los cortos años de vida que nuestra Universidad cuenta no ha habido tiempo para que se arraiguen esas tradiciones del clasicismo que en las universidades antiguas de Europa suelen ser rémora del progreso científico.

Fundadas aquellas universidades en una época en que todos los estudios humanos, a diferencia de los estudios divinos de la teología, estaban reducidos a los clásicos griegos y latinos, se formó desde entonces la idea de que era todo uno, la literatura antigua y las humanidades. Pero nuestra Universidad que ha nacido en el siglo más genuinamente científico de la historia, sabe muy bien cuan prodigiosamente se ha ensanchado desde aquella época el campo de los estudios humanos. A la sazón, la riqueza principal de las humanidades no consiste ya en las obras fósiles de la extinta civilización pagana. Relegadas ésas a segundo término, su riqueza principal consiste ahora en aquellas obras admirables que la ciencia moderna ha creado y que guardan en sus páginas, junto con el espíritu vivificante del universo, las leyes que rigen a las tempestades y a las revoluciones, y a los pueblos y a los gobiernos, a la naturaleza y a la humanidad.

Igualmente virgen se encuentra nuestra Universidad de esas preocupaciones literarias de algunos institutos docentes del antiguo mundo, según las cuales la educación por excelencia del ingenio no consistiría en enseńarle a conocer la verdad y el bien, sino en adiestrarlo en el arte de expresarse con elegancia y pulimento. Creo yo, señores, que todos los actos de los seres morales deben tener una finalidad moral; que, por consiguiente, así como no es lícito escribir por escribir ni hablar por hablar, no lo es tampoco enseñar a hablar por hablar, enseñar a escribir por escribir; y que preferir en la enseñanza nacional la literatura a la ciencia, tanto vale como sacrificar deliberadamente el concepto a la forma, perdiendo en peligro real del espíritu mucho más que lo que se pudiera ganar en cultura externa.

Lo que hoy se apellida literatura, esto es, el conjunto de producciones intelectuales sin intención moral, ni concepto filosófico, ni enseñanza científica, no fue conocido en la historia sino en las épocas de decadencia de las sociedades. Fue en las épocas de decadencia de Grecia y de Roma, cuando aparecieron y se desarrollaron, como los hongos en los terrenos húmedos de nuestros fértiles valles los banales imitadores de Esopo y de Fedro, los retóricos rimbombantes, los gramáticos apegados a la letra y a las virgulillas y los panegiristas de oficio, menguados ensalzadores del vicio y el despotismo. Fue entonces cuando se vieron por primera vez ingenios superiores que, convertidos en relamidos literatos, no se atrevían a decir libremente lo que no se atrevían a decir libremente lo que pensaban, temerosos de que la forma de la expresión ofendiera los castos oídos de los gramáticos. Fue entonces, en fin, cuando al encontrarse en presencia de los emperadores, en vez de exponerles los males que corrían al Imperio, en vez de fijarles el 
rumbo que debían imprimir a la nave del Estado, los sabios del paganismo se ceñían a entonar loas de adularía y a declamar discursos de aparato, dejando que los pensadores de la nueva filosofía, dejando que los Atanasios, los Lactancios y los Ambrosios monopolizaran por completo la independencia del espíritu y reivindicaran para la cristiandad los fueros de la dignidad humana.

La época actual, señores, en que yace rota la unidad de creencias; época en que, por falta de una filosofía general, los escritores que viven del vulgar aplauso tienen que dedicarse a componer oras de mero entretenimiento auditivo, y que ocultar o paliar cobardemente sus opiniones para medrar; época en que los públicos más cultos viven enamorados de la forma y en que la belleza sirve de patente de indemnidad de la obscenidad, es bajo estos respectos del todo en todo semejante a las épocas de decadencia de la civilización grecorromana.

Pero así como a los fines del mundo antiguo empezó a desarrollarse, desdeńada por los retóricos de la filosofía caduca, una literatura nueva, la literatura cristiana, que con ser de formas toscas y rebelde a las leyes de los gramáticos, estaba destinada a moralizar las sociedades y a difundirse universalmente; así en los últimos siglos ha venido surgiendo, surgiendo silenciosa, pero irresistiblemente una nueva literatura, cuyas obras, desdeñadas por los retóricos de moda y por los rancios filósofos de la escolástica, encierran en sí los frutos más estupendos del espíritu humano y mil secretos y virtudes ocultas de la ciencia, para rejuvenecer las sociedades, para reestablecer el orden moral, para dar nuevo vigor a los gobiernos, para inspirar nuevos y más excelsos ideales al arte.

De aquí proviene que en los Estados cultos de nuestros días, la mejor política será, como en la época de descomposición del mundo antiguo, como en la época del gran Constantino, aquella que adopte más prontamente un sistema general de educación pública fundado en la nueva filosofía. Precisado por sus propia destinación a mantenerse por encima de todas las sectas y partidos, el Estado está lógicamente forzado a la adopción de este sistema, porque de todas las enseñanzas, la única que todos aceptamos como verdadera, la única que no nos divide es la enseñanza de la ciencia. Especialmente hoy, ante la tentativa que se hace para ocasionar en la sociedad chilena un fraccionamiento análogo al que trae convulsa y debilita a la sociedad bel$\mathrm{ga}^{4}$, el Estado debe más resueltamente que nunca las uniformes tradiciones de nuestra política docente. Reserve, pues, exclusivamente para sí todas aquellas prerrogativas jurídicas, como la colación de grados, que solo en virtud de una delegación expresa de su soberanía, pueden ser ejercidas por autoridades extrańas. Cuídese de ceder a otras manos fuerzas y armas que conjuntamente servirían para combatirlo a él y para ahondar las divisiones en la sociedad chilena. Contrarreste decididamente la influencia sectaria de una enseńanza que propende derechamente a reaccionar contra el desarrollo de nuestra cultura social, con la influencia moderadora de 
una enseñanza puramente científica, que no vulnera los fueros de ninguna conciencia. Y sobre todo, ponga los institutos de instrucción pública en condiciones de superioridad tal, que todo padre de familia se sienta inclinado a preferirlos para la educación de sus hijos.

En particular, es necesario que la Universidad, expresión la más elevada de nuestra cultura intelectual se convierta cuando antes en una institución realmente nacional por su carácter y por sus funciones. Llamada, como corporación docente, a desarrollar la ciencia, corresponde a ella como poder espiritual, como "superintendencia de la instrucción pública", imprimir a la enseñanza nacional el doble sello de la aplicabilidad y de la unidad científica, y mantener perennemente encendida en este suelo la luz de la filosofía.

Es en este doble carácter, señores, y solo en este doble carácter, como la Universidad está destinada a ser un medio social de gobierno, propendiendo a restablecer y conservar la unidad del espíritu nacional, y a contrarrestar y neutralizar las tendencias perfectamente legítimas, pero inevitablemente dispersivas de las sectas y de los partidos.

En suma, institución sin antecedentes en nuestro pasado, planta arraigada que no germinó de semilla, creación hecha de la nada por el Estado chileno, es la enseñanza nacional como una obra que, para realizarse, ha tenido que elaborar por sí misma sus propios materiales. Inspirados por una clara percepción de las necesidades de la República, los padres de la patria, en quienes la elevación de miras suplía con creces a la falta de saber, le dieron forma y vida a costa de sacrificios indecibles. La patria misma (se puede decir), cuando su propia existencia no estaba todavía bien afianzada ni contaba aún los tiernos ańos de una nińa núbil, la adoptó como hija predilecta entre todas las instituciones públicas y la nutrió con maternal solicitud a costa de su débil ser.

La enseñanza nacional, por consiguiente, es por su historia no menos que por los frutos que rinde a la cultura de esta sociedad, la obra más genuinamente chilena y más esencialmente patriótica del Estado. Todos los chilenos estamos interesados en conservarla para bien de la República, y obligados a custodiarla contra las osadías de un doctrinarismo extraviado. Chile no sería por su cultura el primero de los Estados americanos, sería el último de ellos, como fue durante trescientos años la última de las colonias españolas, si no hubiera dado tan enérgico y perseverante esfuerzo a la enseñanza pública. Los que componemos la cual generación la hemos recibido de nuestros padres como una herencia de cultura misma que no podemos repudiar sin repudiar la cultura misma, y como una herencia amayorazgada e inalienable que nos impone el deber sagrado de transmitirla, a nuestro turno, acrecentada, so pena de cargar con el vituperio de la historia.

\section{EXCMO. SEÑOR, SEÑORES.}

Que en estos deberes y principios se inspire la política y se eduque la juventud de la República, deben ser los deseos de todo sincero amante de la patria y de la ciencia. 